\title{
HIVIAIDS Treatment in Developing Countries: Guyana's Approach
} Leslie Ramsammy*

\author{
Address: Minister of Health \\ * Corresponding author $\ddagger$ Presenting author
}

from 2005 International Meeting of The Institute of Human Virology Baltimore, USA, 29 August - 2 September 2005

Published: 8 December 2005

Retrovirology 2005, 2(SuppI I):SI30 doi:I0.II86/I742-4690-2-SI-SI 30

Diagnostic and treatment tools for HIV are well known and are widely available today. Equitable accessibility to these tools is a major area of concern. The WHO estimates that about $7 \mathrm{M}$ persons are in need of ARV therapy in low and middle-income countries around the world. The WHO "3 $\times 5$ " initiative, launched in 2003, intended to have brought $\mathrm{ARV}$ treatment to at least $3 \mathrm{M}$ persons by the end of 2005. By June 2005, only about 970,000 persons in low and middle-income countries were receiving ARV treatment. Latin America and the Caribbean lead the way with about $62 \%$ of those I need receiving ARV treatment. North Africa and the Middle East (5\%) and Sub-Sahara Africa (11\%) showed the lowest accessibility.

Before 2001, very few low and middle-income countries had an ARV-based treatment program. Brazil had started local production of ARVs, ignoring patents owned by the large multinational $R \& D$ pharmaceutical giants. This move enabled Brazil to provide universal treatment to PLWHA. Other Latin American countries developed ARVbased treatment programs by 2000 also. These countries included Argentina and Mexico. In the Caribbean, the Bahamas, Barbados, Jamaica and Trinidad and Tobago, mainly through World Bank loans initiated ARV-based treatment programs, although at highly unsustainable cost. Indian pharmaceutical companies, such as CIPLA and Ranbaxy began the generic production of a number of ARVs, including the combination cocktail of LSN and these cheaper versions of the ARVs were made available to many African countries. Thus, by 2001, albeit at a painfully slow and glacial pace, access begun to improve in low and middle-income countries. Today, massive injection of funds have began to flow and generic version of the ARVs are far more accessible, yet overall, less than $20 \%$ of PLWHA in low and middle-income countries have access to ARV-based treatment.
One resource-poor country that is changing the poor access to ARVs is Guyana, one of the poorest Caribbean countries. In 2004, the World Development Report ranked Guyana, in terms of the HDI, at 103. Guyana is a HIPC country. Guyana has an HIV prevalence of between 3.5 to $5.5 \%$. It is estimated that about 3,000 persons are in need of ARVs. By 2001, no formal ARV-based treatment program existed. Today, approximately 1,000 persons are on ARV treatment program. Guyana benefits from funding through the Global Fund, the World Bank and is one of the PEPFAR countries. There are also technical assistance through CIDA, PAHO/WHO and UNICEF.

Guyana also has offered universal treatment, including ARVs and laboratory testing for CD4 to everyone living with HIV and who reaches the criteria established for the initiation of treatment. However, roll out to reach everyone who needs to be on ARV treatment has been slow due to constraints of capacity. Still, the treatment program is considered to be one of the success stories in the fight against HIV/AIDS. Thus, far, the ARVs used in the treatment of HIV/AIDS patients have been generic ARVs produced by a local company, the New GPC. There are 15 locally produced formulations and combination therapy with LSN can be obtained at a cost of \$US140 per patient annually. 